\title{
Analysis of Water from some Dams in Katsina State, Nigeria
}

\author{
Fatima B. Suleiman ${ }^{1 *}$, Abdul A. Audu ${ }^{2}$ \\ ${ }^{1}$ Department of Chemistry, Federal College of Education, Katsina, Nigeria \\ ${ }^{2}$ Department of Pure and Industrial Chemistry, Bayero University, Kano, Nigeria
}

\begin{abstract}
The study was conducted to assess seasonal variations in some parameters of water collected from seven different dams in Katsina State, Nigeria using standard procedures. The samples were collected from five locations situated in the east, west, north, south and midpoint in each of the seven dams in the rainy season, harmattan and dry seasons for two years. The temperature, $p H$ and Dissolved Oxygen content of the samples were measured in-situ at the site of collection using a Brannan mercury thermometer, Wagtech international potatest portable $\mathrm{pH}$ meter and an auto cal Dissolved Oxygen meter respectively. Other parameters tested are Turbidity which was measured using a HACH 2100N Turbidimeter while Total Solid, Total Suspended Solid and Total Dissolved Solids were determined using gravimetric method. The average reading for the two years was used in the analysis. The maximum temperature values were obtained in the dry season and lowest in harmattan. The mean conductivity values for all the samples was found to be highest in the dry season and lowest in the rainy season. All the values were however within the $1200 \mu \mathrm{Scm}^{-1}$ Maximum Acceptable Limit recommended by WHO. The Turbidity and Dissolved Oxygen values were found to be highest in the rainy season. The turbidity values for all the samples were above the 5NTU Maximum Acceptable Limit for drinking water. The $\mathrm{pH}$ values for all the samples collected were within the recommended range of 6.5-8.5 with the values being generally highest in the dry season. The conductivity values and Total Dissolved Solids showed no significant direct correlation at 95\% confidence level in all the seasons studied. But the Turbidity and Total Suspended Solids showed a direct correlation in the rainy season and harmattan at $95 \%$ confidence level. The parameters studied showed variations with seasons and locations of the dams. ANOVA showed a significant difference $(p<0.05)$ between the different seasons in conductivity, $p H$, Dissolved Oxygen and temperature while turbidity values indicated no significant difference $(p>0.05)$ in the seasons studied . From the results obtained it was concluded that seasonal variation affects water quality due to changes in parameters such as $\mathrm{pH}$, conductivity, Dissolved Oxygen and Total Solids. The variations may also be influenced by location of the dams, time of sampling, and activities carried out around the dams. Recommendations forwarded include the need for regular water quality monitoring which should include trace metal levels, nutrients and microbiological analysis.
\end{abstract}

Keywords: Analysis, dams, water, Katsina.

\section{Introduction}

Water is a vital resource to support life on earth. Unfortunately, it is not evenly distributed over the world by season or location. Water is essential for the survival of mankind and the future development of the world cities, industries and agriculture. As the world's population continues to grow so does the demand for water ( ICOLD,1999). One of the most efficient ways to manage water resources for human needs is by the construction of dams that create reservoirs for storage and future distribution (ICOLD, 1999; Asmal, 2009).

Water quality and the concentration of some metals usually vary in water with seasons according to changes in some parameters such as conductivity, $\mathrm{pH}$, dissolved oxygen and total solids. Major metal concentrations are naturally variable from one season to the other in water according to changes in environmental conditions such as temperature, turbidity, dissolved oxygen and redox potential as well as increases in the decay of organic matter which cause the release of metals to overlying water ( Taufeek and Korium, 2009).

Human beings and other living organisms require certain food substances in form of mineral salts or nutrients for their general well-being. These they get from the food they eat and water they drink. Properly planned, designed, cited, constructed and maintained dams contribute significantly towards fulfilling the water supply requirements, improves economy, and boost food production ( ICOLD, 1999; Shariff, 2009; Yakubu, 2009) of communities. It is therefore important that studies are conducted to ascertain the quality of water which can affect the quality of plants grown around the dams and aquatic animals in the water in order to ensure the healthy growth of the citizenry. The dams used in this study supply Katsina state and its environs with potable water. Some communities around the dams use the untreated water for drinking, laundry, irrigation and other domestic purposes. The study was therefore conducted to assess the seasonal variations in some parameters in the water and to find out if the values are within the recommended values for drinking water in order to ascertain its safety or otherwise of its use for domestic uses by the citizenry. 
Study Area

\section{Materials And Methods}

Katsina State is located in Northern Nigeria. It is between latitude $11^{\circ} 02$ ' and $13^{\circ} 13^{\circ}$, longitude $6^{\circ} 05^{\prime}$ and $9^{\circ} 20^{\circ}$, It occupies $24,1929 \mathrm{~km}^{2}$. It is bounded in the east by Kano and Jigawa States, in the west by Zamfara State, in the North by Niger Republic.

The State is one of the few states in Nigeria where crops are grown all year round. Apart from farming during the rainy season, dry season farming is done along river banks and along the numerous dams built by the State and Federal Government( Katsina State of Nigeria, 2009). The dams used in this study are Ajiwadam(AJI), Dutsinma dam(DTM), Zobe dam(ZOB), Jibia dam(JIB), Malumfashi dam(MLF), Mairuwa dam(MAI) and Gwaigwaye dam(GWA).

Figure 1 is the map of Katsina State showing the location of the dams used in this study.

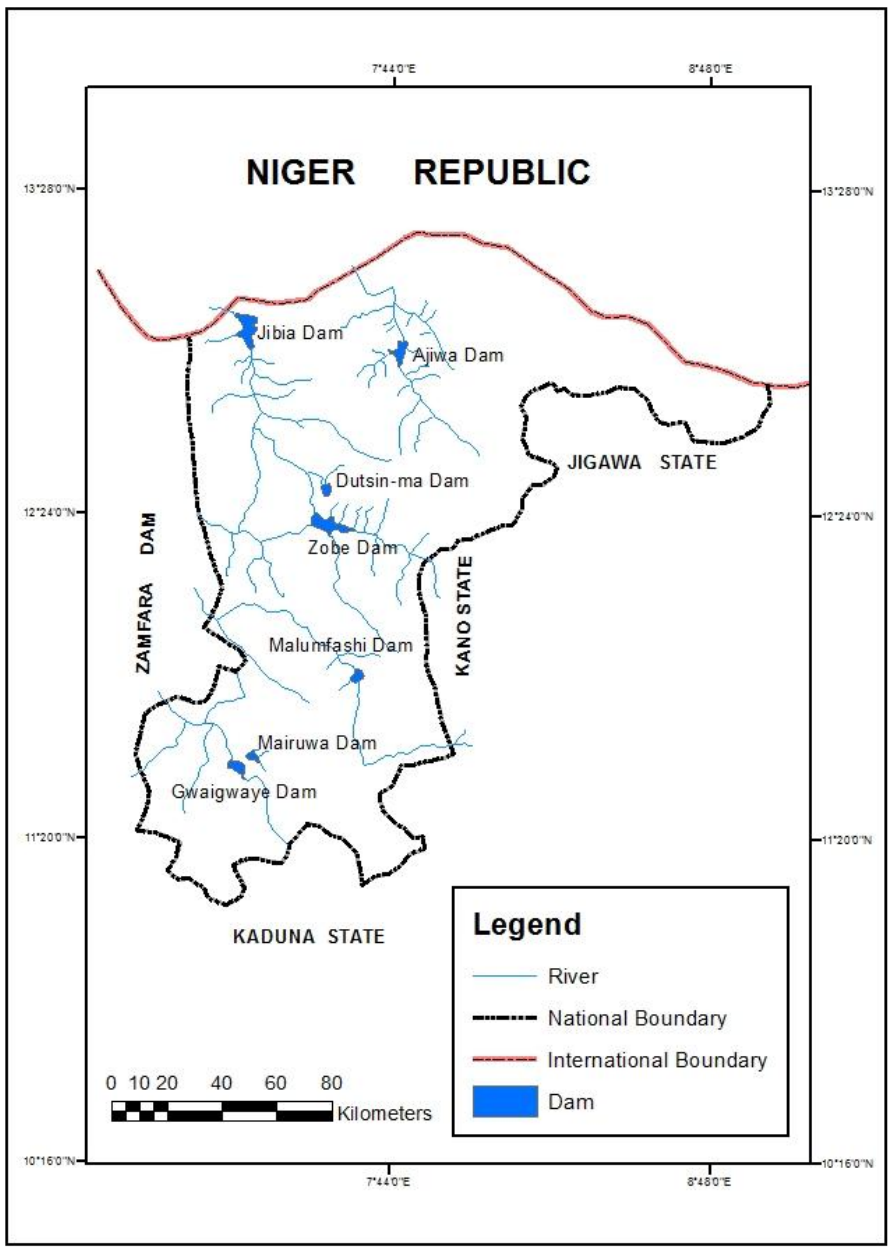

Map of Katsina State Showing Dams (Study Location)

\section{Materials and Methods}

Analar grade reagents were used throughout the study. Deionised water was used for all solution preparations. All glasswares and plastic containers were washed thoroughly with detergent solutions, rinsed with tap water and then with deionised water before drying. 
Analysis of Water from some Dams in Katsina State, Nigeria.

\section{Sample Collection}

Water samples were collected from Ajiwa, Dutsinma, Gwaigwaye, Jibiya, Mairuwa, Malumfashi and Zobe dams in Katsina State in the rainy season, harmattan( the coldest season of the year) and dry seasons for two years using standard procedures. A total of 35 water samples were collected from the seven dams on surface water level by immersing the sample containers nozzle down 0.5 meters and slowly allowing them to fill (APHA, 1992). Pre-cleaned one liter polythene containers were used to collect the samples from five locations situated in the east, west, north, south and midpoint in each of the seven dams. The five samples collected in each dam were thoroughly homogenized after collection from which the sample used for the analysis was taken. The average reading was used in the analysis of the result.

\section{METHODS OF ANALYSIS}

The temperature, $\mathrm{pH}$ and Dissolved Oxygen content of the samples were measured at the site of collection using a Brannan mercury thermometer, Wagtech international potatest portable $\mathrm{pH}$ meter and an auto cal Dissolved Oxygen meter respectively using standard procedures ( APHA,1992 and Standard Analytical procedures,1999).

Turbidity was measured in the laboratory with a HACH 2100 N Turbidimeter and Total Solid, Total Suspended Solid and Total Dissolved Solids were determined using gravimetric method( APHA,1992 and Standard Analytical procedures,1999). Readings were taken in the rainy season, harmattan and dry seasons for two years. The average values for the two years were used in the analysis of result.

\section{Temperature}

\section{Results/ Discussion}

Figure 2 shows the mean temperature values in water for the three seasons. In this study, the temperature values were maximum in the dry season and generally minimum in harmattan. The average value in the rainy season was $33.76 \pm 1.05^{\circ} \mathrm{C}, 31.67 \pm 2.32^{\circ} \mathrm{C}$ in harmattan and $34.31 \pm 0.69^{\circ} \mathrm{C}$ in the dry season. The low temperatures recorded in harmattan may be due to the cold harmattan breeze and lower atmospheric temperature while the high values in the dry season may be due to low water level and high atmospheric temperature. The lower values in the rainy season when compared to the dry season may be due to higher water level. Water temperature influences many physical, chemical and biological processes and the rate of chemical reactions generally increases at higher temperatures. Seasonal variations in water temperature depends on where they are located (Perlman, 2013). Shinde, Pathan, Raut and Sonawane(2011) reported a similar result with a minimum temperature in winter (the colder season) and a maximum in summer. Statistical analysis of the values using ANOVA showed a significant difference $(\mathrm{p}<0.05)$ in the different seasons.

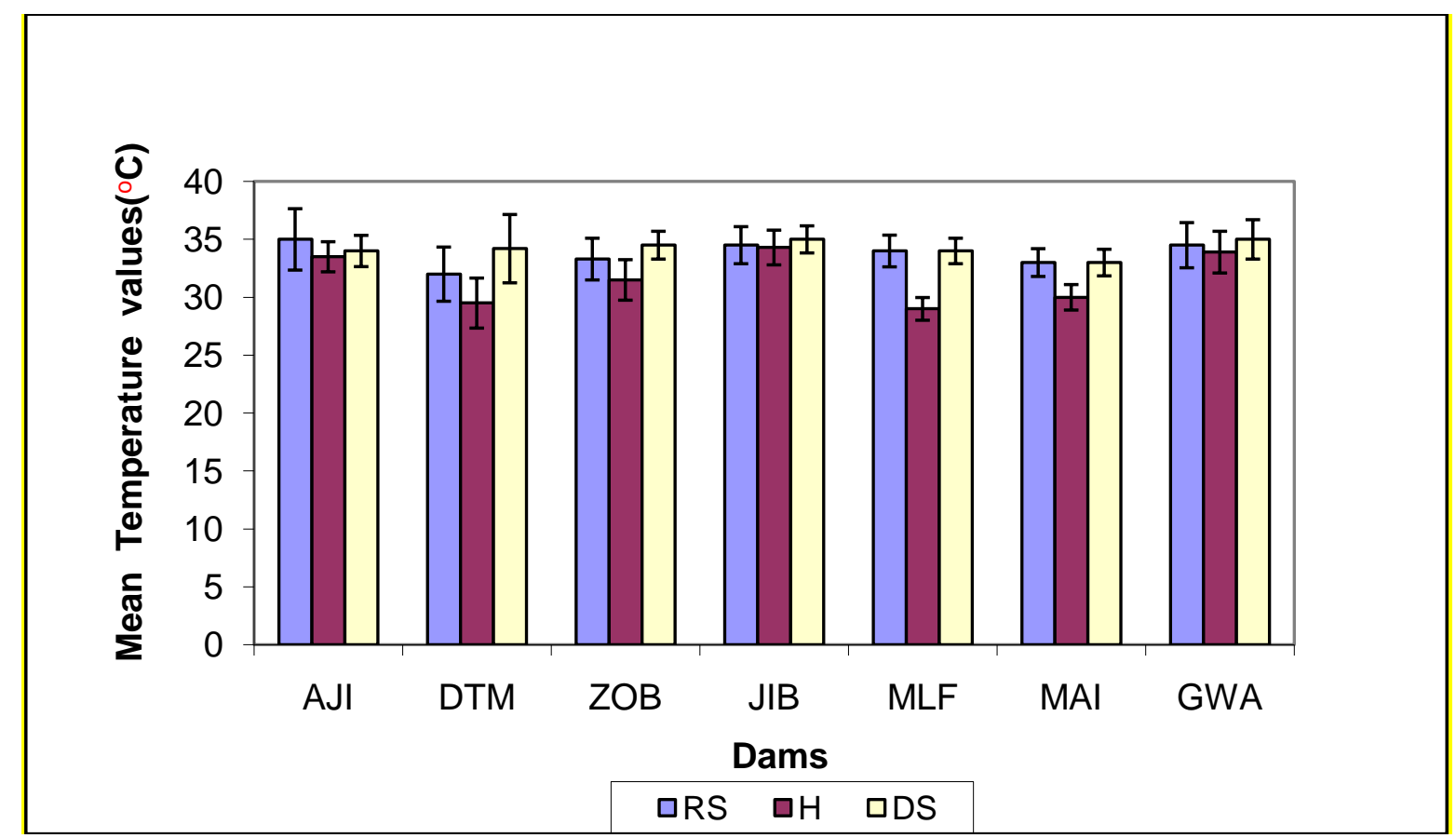

Figure 2: Mean temperature values in water in the rainy season (RS), Harmattan(H) and Dry seasons(DS) 


\section{Conductivity}

Figure 3 shows means conductivity values for the three seasons.

Conductivity is a measure of the ability of water to pass an electrical current and is affected by the presence of dissolved solids. The ability depends on the presence of ions, their total concentration, mobility, valence, relative concentrations and temperature of measurement (Shinde, Pathan, Raut and Sonawane,2011). Discharges into water can change conductivity depending on their nature. The mean conductivity values for all the dams studied were higher in the dry season and lowest in the rainy season. This may be due to dilution of the water in the rainy season and evaporation in the dry season. Mairuwa dam had the highest conductivity in all the seasons which may be due to the rocky nature of the area and possible dissolution of minerals from the surrounding rocks. The higher conductivity values in the dry season may also be attributed to the higher water temperatures in the season as at high temperatures water can dissolve more minerals. The relatively high values in Dutsinma and Malumfashi may also be due to their relatively higher rocky nature when compared to the other dams. All the values are however within the $1200 \mu \mathrm{Scm}^{-1}$ maximum acceptable limit recommended by WHO (Saeed,2008). Higher dry season conductivity values were also reported in earlier studies by Shinde, Pathan, Raut and Sonawane,2011; Saeed,2008: Oyhakilome,Aiyesanmi and Akharayi(2012);Abolude,Davies and Chia,2009; and Ibrahim, Auta and Balogun, 2009. Analysis using ANOVA showed a significant difference $(p<0.05)$ between the values obtained in the different seasons.

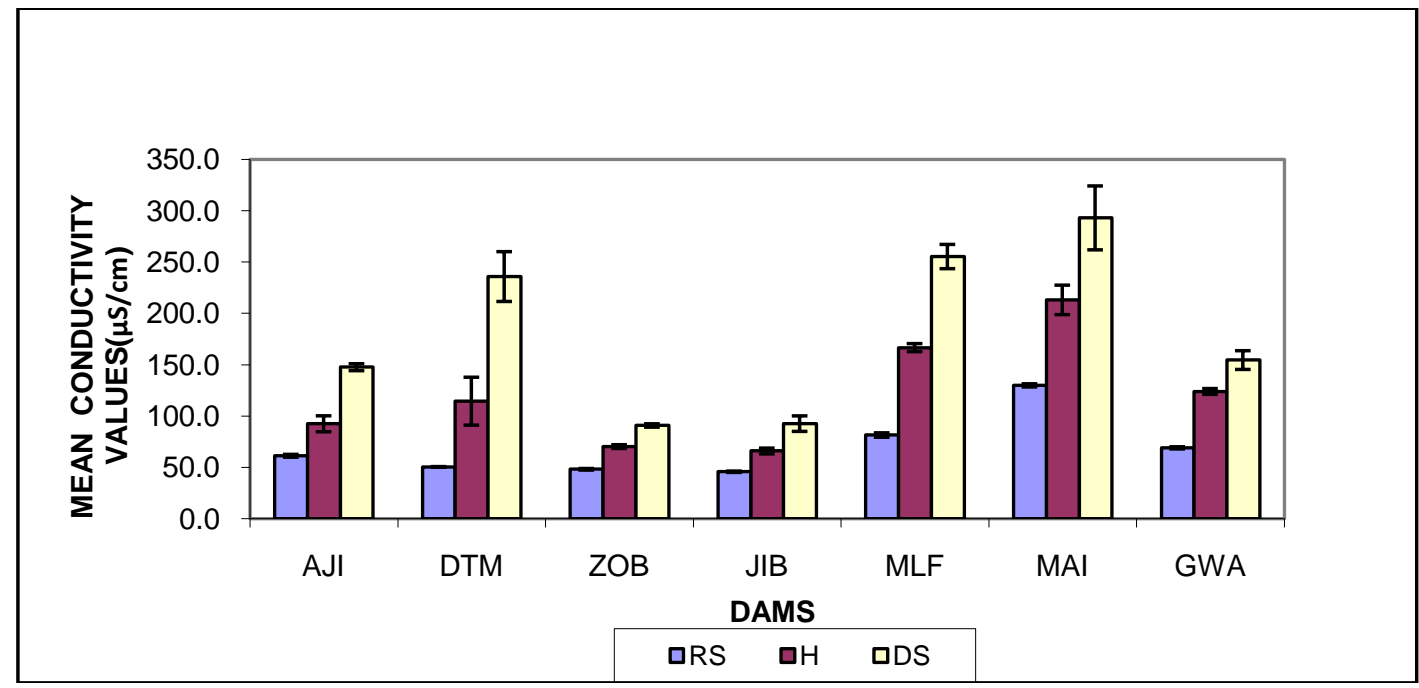

Figure 3: Mean conductivity values of water in the rainy season, harmattan, and dry season samples.

\section{Turbidity}

Figure 4 shows the mean turbidity values in the three seasons.

Suspension of particles in water interfering with the passage of light is called turbidity (Shinde, Pathan, Raut and Sonawane,2011). It is caused by a wide variety of suspended matter that range in size from colloidal to coarse dispersion depending on the degree of turbulence and may include inorganic and organic substances. The mean turbidity values in this study were highest in the rainy season and lowest in the dry season samples. All the turbidity values were above the 5NTU which is the accepted limit for drinking water. The high turbidity values in the rainy season can be attributed to run-off into water bodies. The relatively low turbidity values in Mairuwa, Dutsinma and Gwaigwaye dams may be because the areas around the dams are rocky in nature. In addition there are a lot of trees and other plants around Mairuwa dam which may trap some of the solid particles washed by the rain and prevent them from getting into the dam. The high values in Jibia can be due to the sandy nature of the area. Suspended matter can contain toxins such as heavy metals and biocide and can also harbor microorganisms (Oyhakilome, Aiyesanmi and Akharayi,2012). Higher turbidity values were also obtained in the rainy season in earlier studies conducted by Saeed (2008) and Oyhakilome,Aiyesanmi and Akharayi(2012). Ladipo, Ajibola and Oniye (2011) reported no seasonal pattern in turbidity. ANOVA showed no significant difference $(p>0.05)$ between the values obtained in the different seasons in this study. The study by Oyhakilome ,Aiyesanmi and Akharayi (2012) also showed no significant difference in turbidity values in the seasons studied, they also obtained values above the recommended 5NTU. 


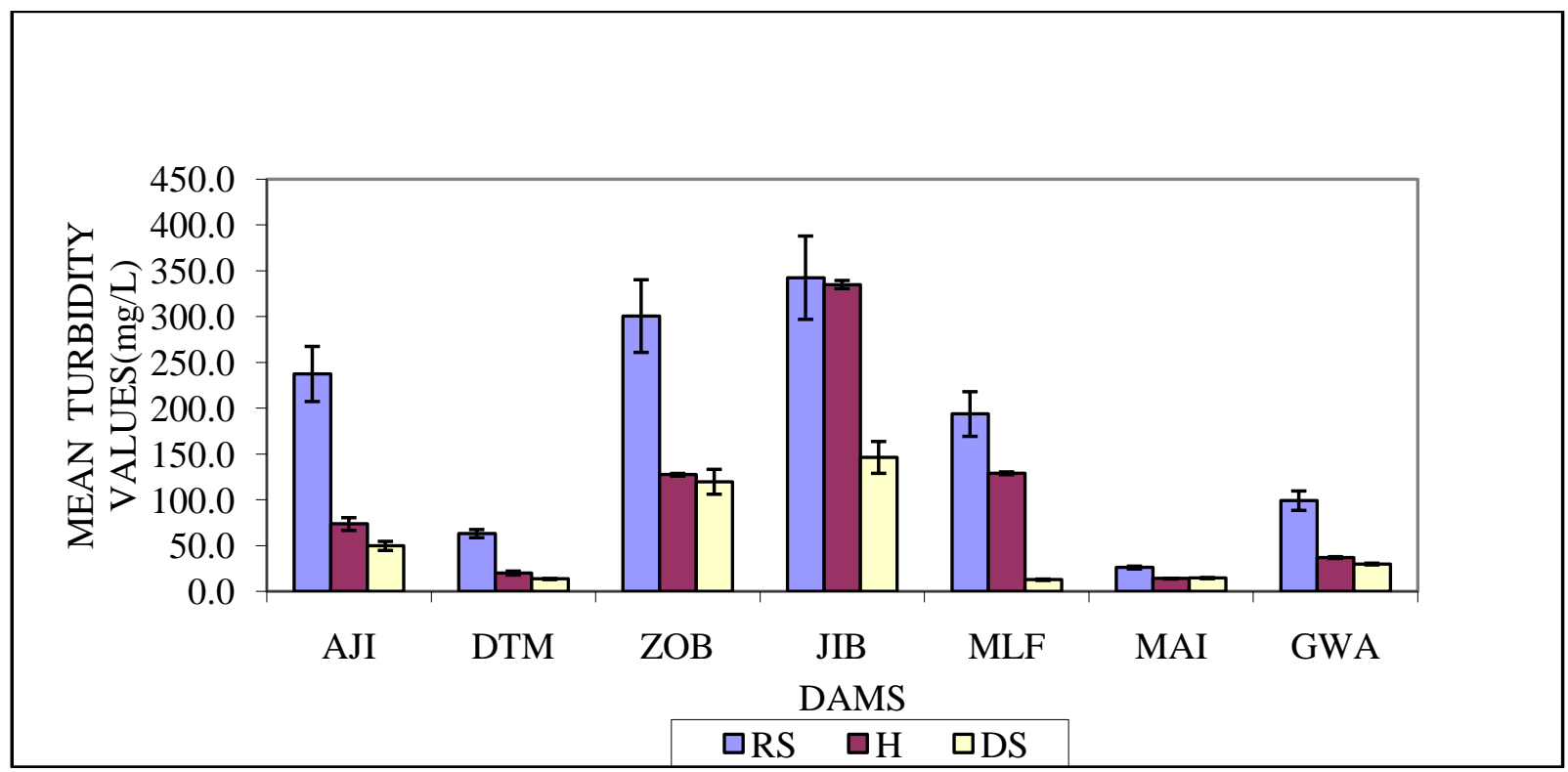

Figure 4: Mean turbidity values in water in the rainy, harmattan and dry seasons

\section{Dissolved Oxygen}

Figure 5 represents the mean Dissolved Oxygen values in water.

Dissolved oxygen is the amount of oxygen that is dissolved in water and is essential to healthy water bodies. Dissolved oxygen levels fluctuate seasonally, over a 24-hour period, vary with water temperature and with altitude. Cold water holds more oxygen than warm water and water holds less oxygen at higher altitudes (APHA, 1992).

The dissolved oxygen values obtained were generally highest in the rainy season and lowest in the dry season. The high values in the rainy season might be due to aeration with continuous disturbance of the water from wind storms usually occurring in the rainy season while the lower value in the dry season could be due to increased water temperature which can reduce the amount of oxygen it can hold. This may also explain the higher values in harmattan when compared to dry season. In this study the Dissolved Oxygen content range from $7.20 \pm 0.11-8.80 \pm 0.10 \mathrm{mg} / \mathrm{L}$ in the rainy season, $6.70 \pm 2.09-7.50 \pm 0.17 \mathrm{mg} / \mathrm{L}$ in harmattan and $4.90 \pm 0.03-$ $7.00 \pm 0.10 \mathrm{mg} / \mathrm{L}$ the dry season. High dissolved oxygen values were also obtained in the rainy season in studies by Oyhakilome, Aiyesanmi and Akharayi (2012). ANOVA revealed a significant difference $(p<0.05)$ in the values obtained in the different seasons.

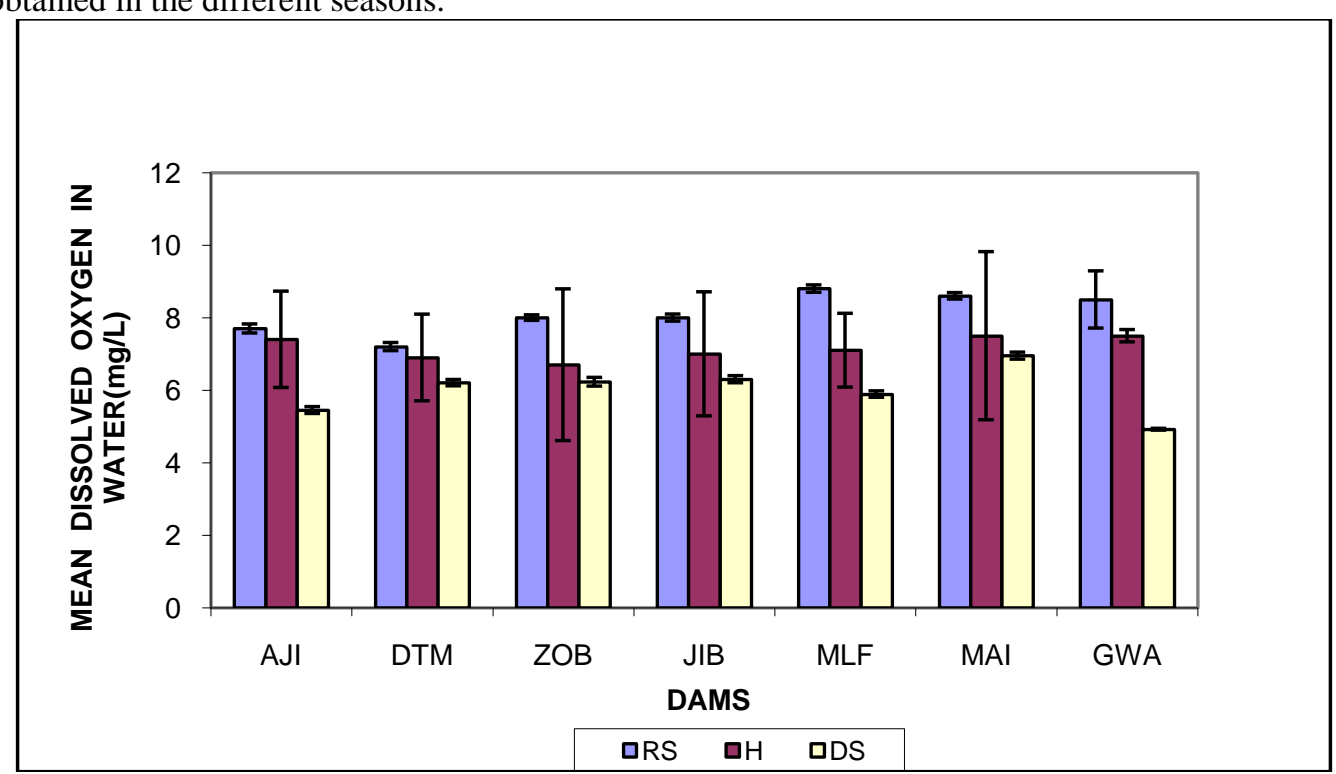

Figure 5: Mean Dissolved Oxygen in water (mg/L) 


\subsection{Comparison of Conductivity and Total Dissolved Solids}

Figures 6,7, and 8 are plots comparing the conductivity values and Total Dissolved solids in water in the rainy season, harmattan and dry seasons respectively.

There seems to be no relationship between the two parameters in all the seasons. A negative correlation was shown between the two parameters at 0.05 level. Papatilippaki, Kotti and Stavroulakis(2008) also stated in their study that the electrical conductivity seems to have no correlation with seasonal variations of dissolved metals. The non correlation between these two parameters could be explained by the fact that the conducting ions in the water are at concentrated levels. Increased particles in the water due to runoff from surrounding lands may be the explanation for the TDS values being much higher than the conductivity values in the rainy season. In solutions of this nature, the proximity of the conducting ions to each other depresses their activities and consequently their ability to transmit current even though the physical amount of dissolved solids is not affected (Lenntech, 2011). Mairuwa dam had the highest conductivity values in all the seasons although it had the lowest TDS values in the rainy season and harmattan. This may be because of dilution of the water due to the high rate of rainfall in the area and the fact that introduction of particles by runoff into the water is minimal because of the nature of the area. The low conductivity values in other dams such as Zobe and Jibia despite their high TDS values could be accounted for by the higher water concentration, increased proximity between the ions and therefore depression of the activity of the ions.

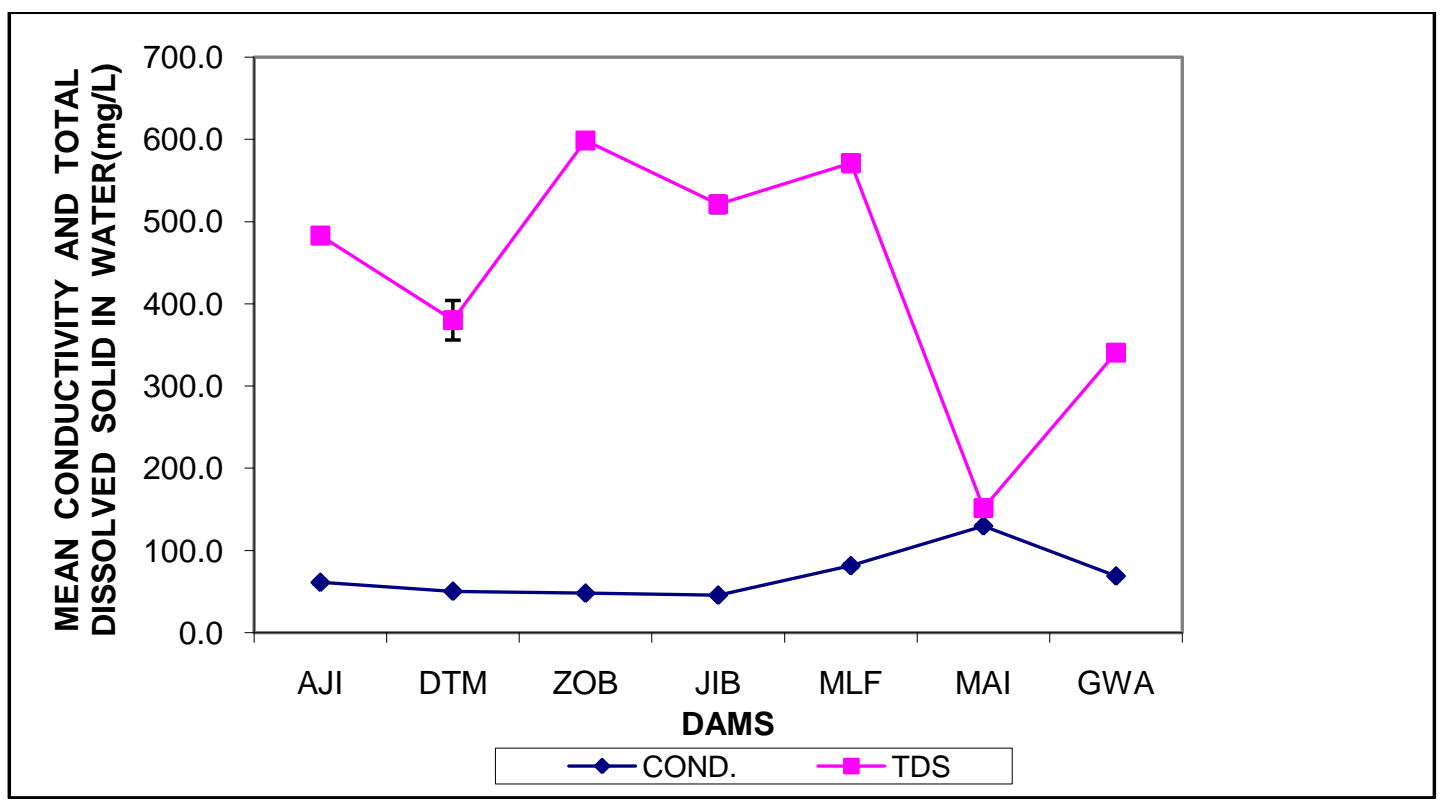

Figure 6: Mean Conductivity and Total Dissolved Solid in water in the rainy season

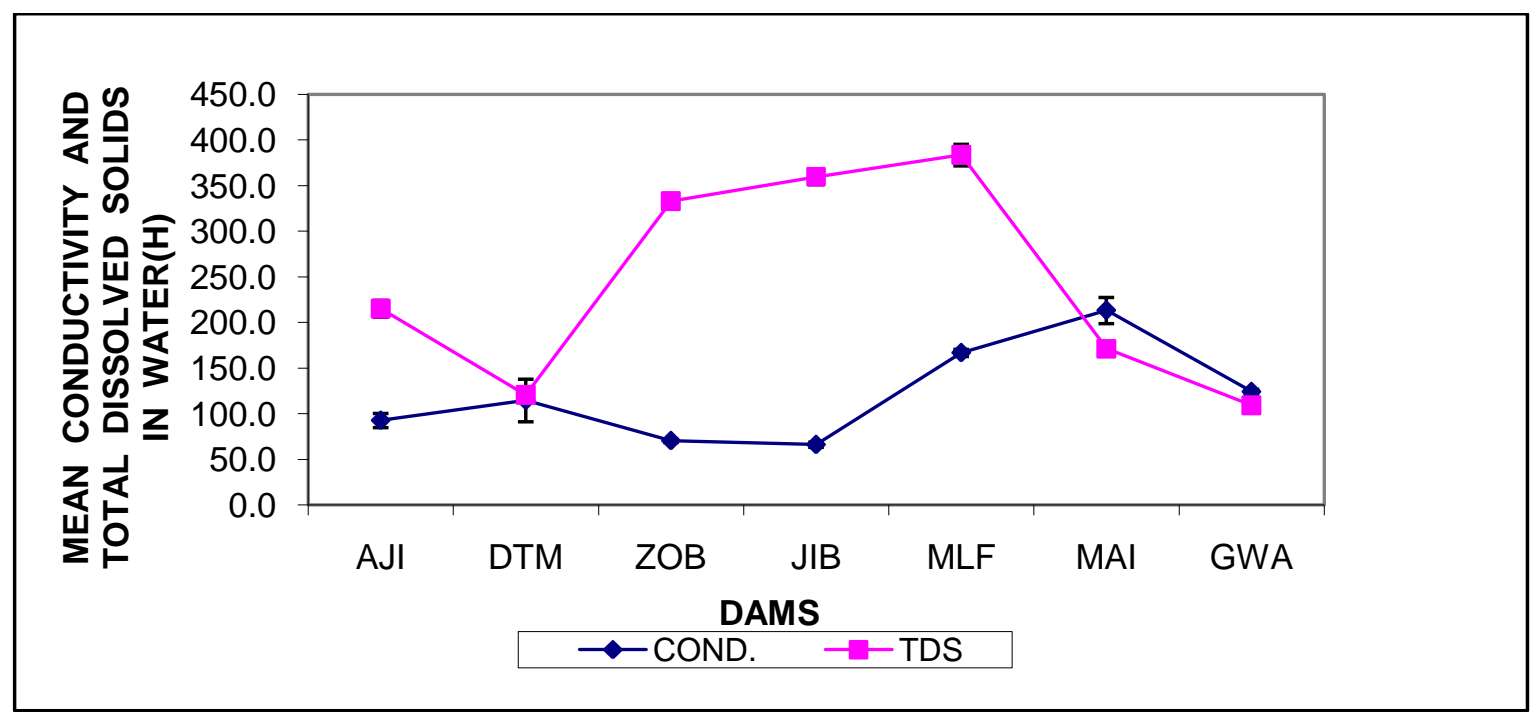

Figure 7: Mean Conductivity and Total Dissolved Solids in water in harmattan 


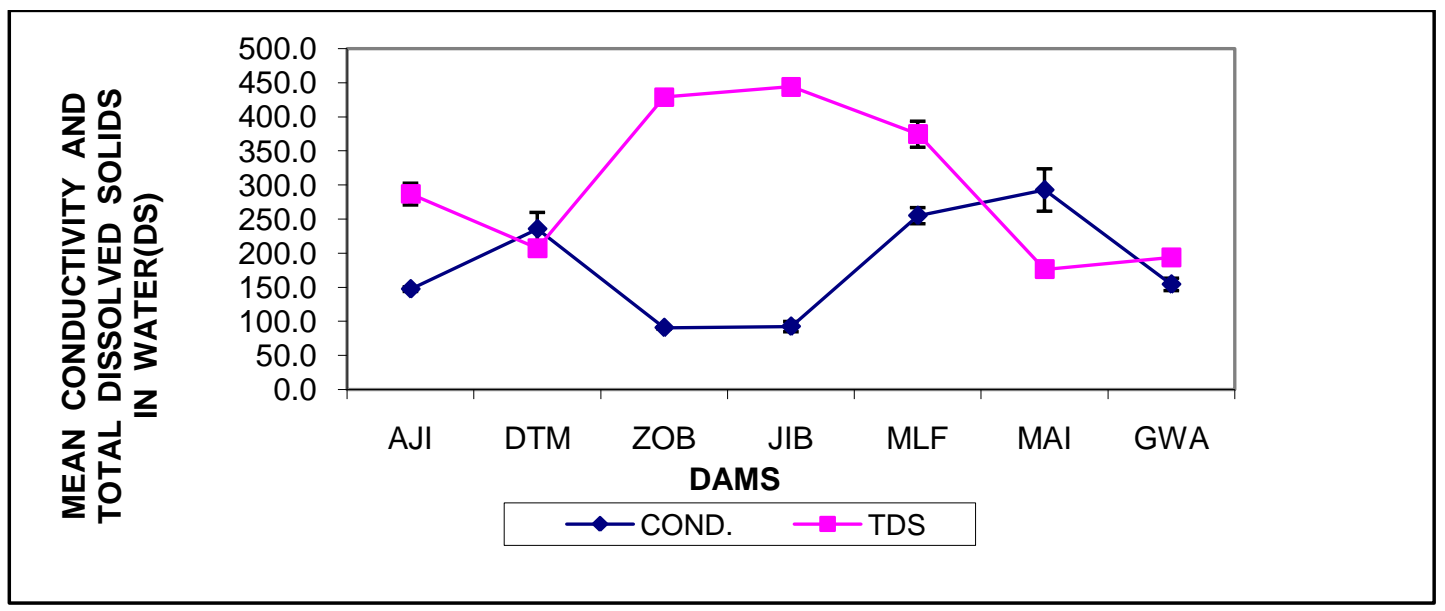

Figure 8: Mean Conductivity and Total Dissolved Solid in water in the dry season

pH

Figure 9 represents the mean $\mathrm{pH}$ values in water in the three seasons.

The $\mathrm{pH}$ of a solution is the negative common logarithm of the hydrogen ion activity (WHO,1996). The $\mathrm{pH}$ values were generally highest in the dry season in this study. Exceptions are Jibia and Mairuwa dams where highest values were obtained in the harmattan season. All the values were however within the recommended range of 6.5 to 8.5. Higher $\mathrm{pH}$ values were obtained in the dry season in studies by Saeed (2008), Oyhakilome,Aiyesanmi and Akharayi(2012), Ladipo, Ajibola and Oniye (2011) and Ogbuagu,Chukwuocha, Okoli and Njoku-Tony(2011). The lower pH values in the rainy season might be due to deposition of some organic matter into water from run-off, dilution of the water and the contributions made by acid rain. No significant difference was observed between dry and rainy season $\mathrm{pH}$ in another study by Abolude, Davies and Chia (2009).

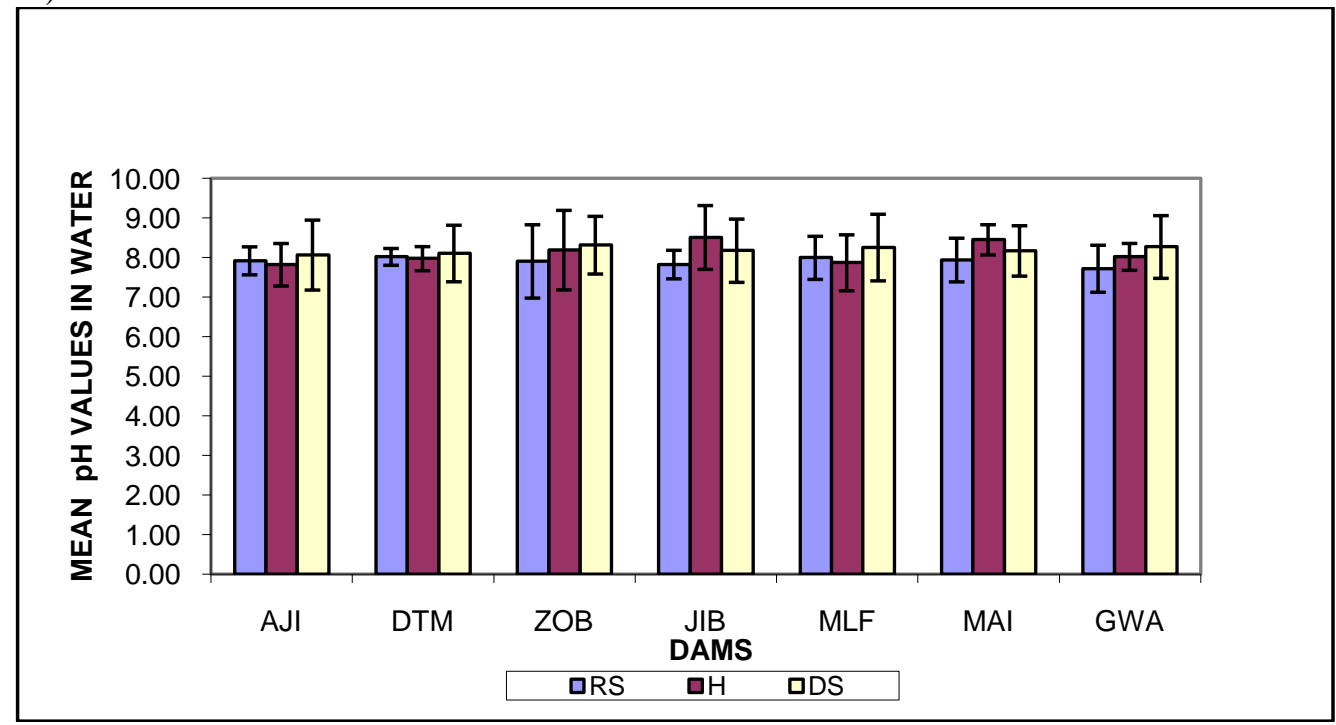

Figure 9: Mean $\mathrm{pH}$ values in water.

\section{Comparison of Turbidity and Total Suspended Solids(TSS) in water}

Figures 10,11 and 12 show a comparison between the Turbidity and Total Suspended Solids in water in the rainy season, harmattan and dry season respectively. Comparison using Pearson correlation showed a moderate positive correlation between the two parameters in the rainy season and a substantial positive correlation in harmattan with correlation coefficients 0.466 and 0.610 respectively while a negative correlation with a value of -0.266 was obtained in the dry season .Ajiwa and Dutsinma dams had high TSS values in the dry season but their turbidity values were relatively low which might be because of the weight of the suspended particles thereby increasing TSS values but are not measured by the turbidity meter because they settle before the reading is taken. This also points to the influence of varying human activities around the dams. Malumfashi dam consistently had higher TSS but lower turbidity values when compared to Jibia dam which may be explained by the colour of the suspended particles in Jibia which gives the water a brownish colour resulting in increased turbidity values. In the Dutsinma dam, turbidity values changed from $63.20 \pm 4.45$ in the 
Analysis of Water from some Dams in Katsina State, Nigeria.

rainy season, $20.10 \pm 2.16$ in harmattan to $13.70 \pm 0.62$ in the dry season, while TSS values gradually increased from $29.00 \pm 2.97$ in the rainy season to $81.80 \pm 9.65$ in harmattan and $141.20 \pm 2.66$ in the dry season. The increased turbidity values in the rainy season may be due to disturbance of the water which suspends the surrounding soil and sediments in the water therefore increasing the values. They settle in harmattan and dry seasons but there may be deposits from the harmattan dust and larger particles from dry season farming inputs resulting in high TSS values but with a corresponding low turbidity values in the seasons.

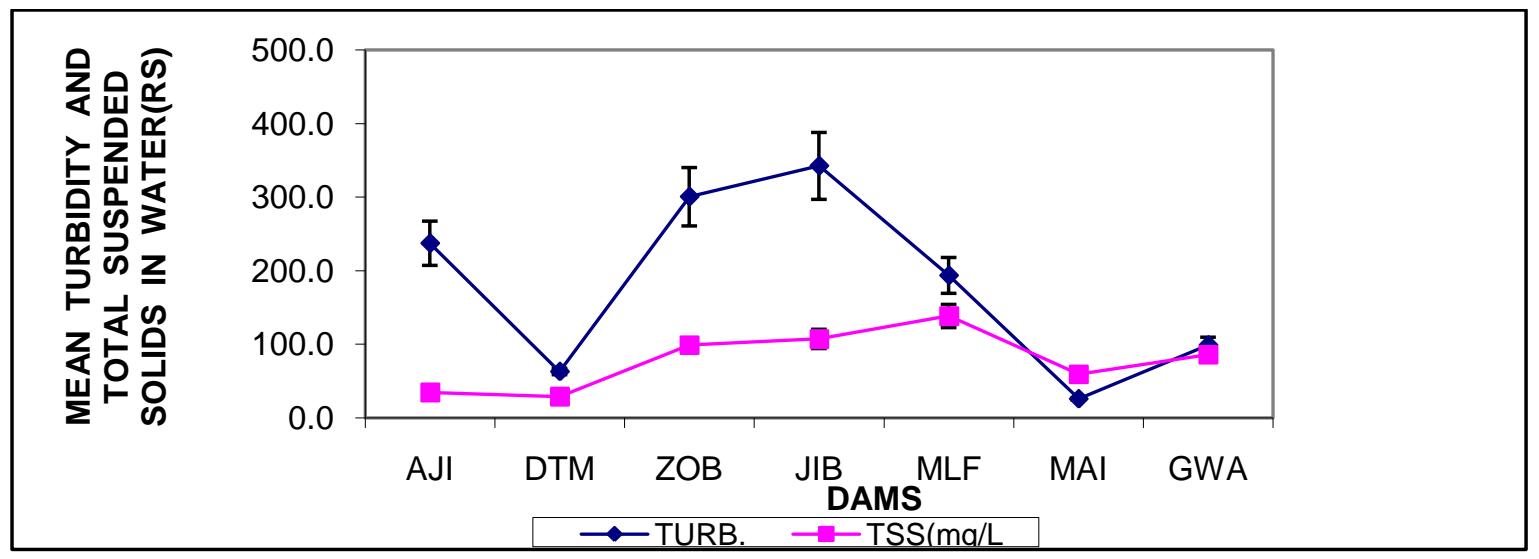

Figure 10: Mean Turbidity and Total Suspended Solids in water in the rainy season.

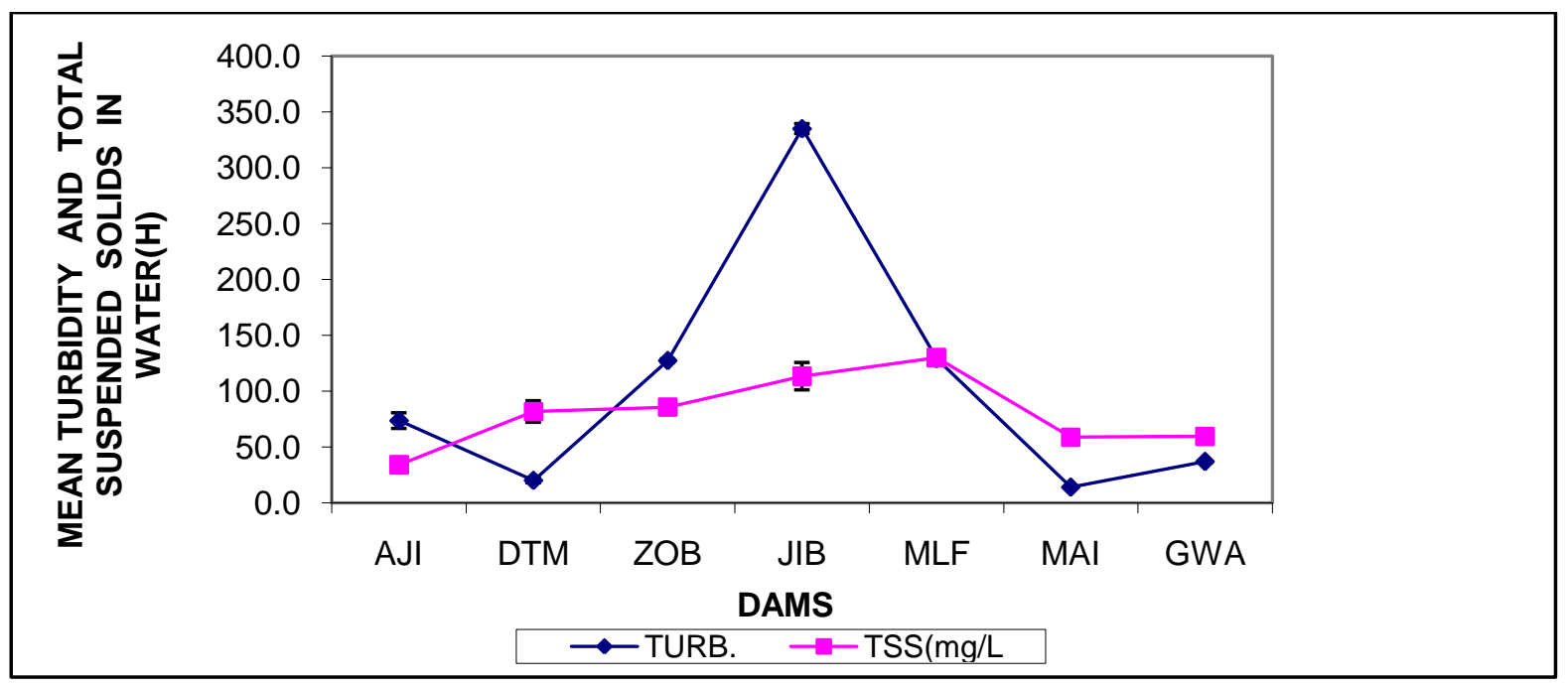

Figure 11: Mean Turbidity and Total Suspended Solids in water in harmattan.

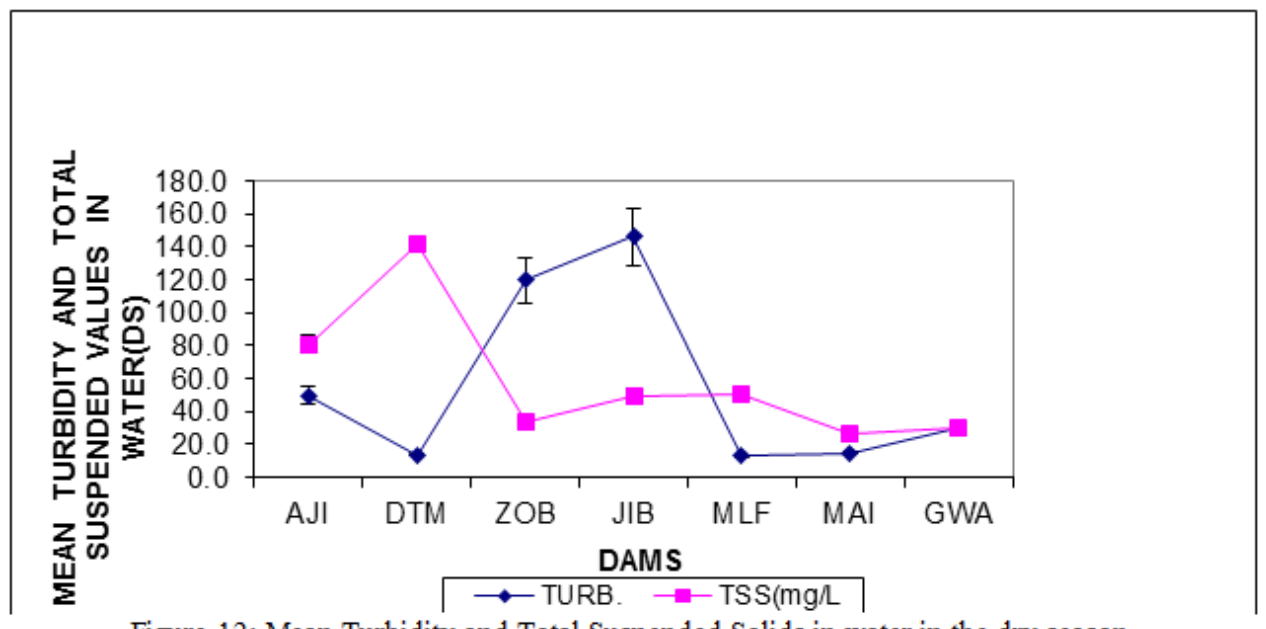

Figure 12: Mean Turbidity and Total Suspended Solids in water in the dry season. 


\section{Conclusion}

The results showed seasonal variations in the parameters studied. ANOVA showed a significant difference $(\mathrm{P}<0.05)$ in conductivity, $\mathrm{pH}$, Dissolved Oxygen and temperature while turbidity showed no significant difference $(\mathrm{P}>0.05)$ in the different seasons. The variations in the studied parameters may be influenced by location of the dams, time of sampling and other human activities such as laundry, rearing of animals, fishing and other agricultural inputs from the irrigation carried out around the dams. It is therefore important that water quality monitoring is carried out periodically to ensure the healthy growth of the citizenry. Activities that can introduce pollutants into water bodies should be discouraged as the pollutants have the ability to get into the food chains causing detrimental effects on the consumers.

\section{References}

[1] Abolude, D.S., Davies, O.A. and Chia, A.M.(2009). Distribution andConcentration of Trace Elements in Kubanni Reservoir in Northern Nigeria. Research Journal of Environmental and Earth Sciences. 1(2): 39-44.

[2] APHA(1992). Standard Methods for Water and Effluent Analysis. $18^{\text {th }}$ edition. American Public Health Association, Washington, D.C.

[3] Asmal,K.(2009). Opening remarks by Professor Kader Asmal Chairperson. The world commission on dams.

[4] http://www.adb.org/NGOs/adb-responses.asp. Retrieved 4/4/2009.

[5] Ibrahim, B.U., Auta, J.,andBalogun, J.K.(2009). An Assessment of the Physicochemical Parameters of Kontagora Reservoir, Niger State, Nigeria. Bayero Journal of Pure and Applied Sciences. 2(1): 64-69.

[6] ICOLD(1999). Benefits and concerns about dams. International commission on large dams.

[7] http://www.swissdams.Ch/-/B and C/Benefits of and concerns about dams.pdf

[8] Katsina State of Nigeria(2009). Nigeriagalleria.com.Nigeria information guide.Nigeria Business Directory Index. http;//www.nigeriagalleria.com/Nigeria/states-free Nigeria/Katsina state

[9] Ladipo,M.K., Ajibola, V.O. and Oniye, S.J.(2011). Seasonal Variations in Physicochemical Properties of Water in some selected locations of the Lagos Lagoon. Science World Journal. 6(4).

[10] Lenntech(2011).Water conductivity. http://www.lenntech.com/applications/ultrapure/conductivity/water-conductivity.htm . Retrieved 14/4/2011.

[11] Ogbuagu, D.H., Chukwuocha, N.A.C., Okoli, C.G. and Njoku-Tony, R.F.(2011). Physicochemical gradients and in situ yields in pelagial primary production of the middle reaches of Imo River in Etche, South-eastern Nigeria.

[12] Journal of Ecology and the Natural Environment. 3(2): 47-53.

[13] Oyhakilome, G.I., Aiyesanmi, A.F., Akharaiyi, F.C.(2012). Water Quality assessment of Owena Multi-purpose Dam, Ondo State, South-western Nigeria . Journal of Environmental Protection. 3: 14-25.

[14] Papafilippaki, A.K., Kotti, M.E. and Stavroulakis, G.G.(2008). Seasonal Variations in Dissolved Heavy Metals in Kertis River, Chania, Greece. Global NEST Journal. 10(3): 320-325.

[15] Perlman, H.(2013). Water Temperature. USGS Science for the Changing World.The USGS Water Science School. U.S. Depatment of the Interior/US. Geological Survey.

[16] Saeed, M.D.(2008). Chemical Analysis of Drinking Water in Kano State. A PhD Thesis submitted to the Department of Chemistry, Bayero University, Kano.

[17] Shariff, U.(2009). Politics of River Basin Authorities. Daily Trust, Tuesday April 14, 2009.p. 11.

[18] Standard Analytical procedures(1999).Standard Analytical Procedures for Water

[19] Analysis. Hydrology project. Government of India and Government of Netherlands.Shinde, S.E., Pathan, T.S., Raut, K.S. and Sonawane,D.L.(2011). Studies onPhysicochemical Parameters and Correlation of Harsool-savangiDam,District Aurangabad, India. Middle-East Journal of Scientific

[20] Research.8(3).544-554

[21] Toufeek, M.A.F. and Korium, M.A (2009). Factors Controlling the Distribution of the Major Metals in Lake Nasser water. American - Eurasian J. Agric\&Environmental Science. 5(6). $804-812$.

[22] WHO(1996).International Programme on Chemical Safety. Guidelines for drinkingWater quality. $2^{\text {nd }}$ Edition, Volume 2. Health Criteria and other Suppoting Information. Geneva.

[23] Yakubu, A.(2008). Nigeria: Experts stake holders Brain Storm Over Lake Chad. Daily Trust. 5/11/2008 Allafrican.com/stories/2008/1050575/html Retrieved 6/7/2009. 